\title{
Editorial Statistics and Best Reviewers Award 2018 for Journal of Korean Neurosurgical Society
}

\author{
Moonyoung Chung, M.D., Bum-Tae Kim, M.D. ${ }^{2}$ \\ Editorial Staff, Journal of Korean Neurosurgical Society; Department of Neurosurgery, Soonchunhyang University Bucheon Hospital, Soonc- \\ hunhayng University College of Medicine, Bucheon, Korea \\ Editor in Chief, ${ }^{2}$ Journal of Korean Neurosurgical Society; Department of Neurosurgery, Soonchunhyang University Bucheon Hospital, Soonc- \\ hunhayng University College of Medicine, Bucheon, Korea
}

We are pleased to announce the editorial statistics and Best Reviewers Award for 2018.

\section{EDITORIAL STATISTICS}

On behalf of the Journal of Korean Neurosurgical Society (JKNS), we would like to once again express great gratitude to all authors for submitting their articles to JKNS in 2018. A summary of the papers submitted to the JKNS is as follows. During the year, we received a total of 236 articles; all submissions were previewed by the Editor-in-Chief, and most were

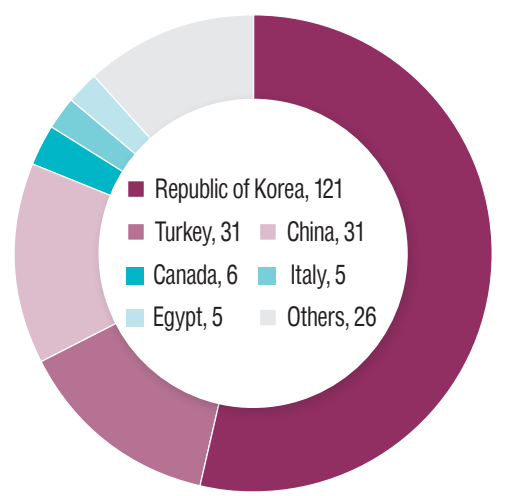

Fig. 1. Number of submitted articles stratified by nationality in 2018 . requested for peer review ${ }^{2}$. Among these articles, 38 are currently under review. Of the remaining 198 articles, 63 have been accepted for publication and 134 have been rejected. Overall, the acceptance rate is $31.8 \%$.

Stratification of the articles by nationality (Fig. 1) revealed that slightly over half $(50.8 \%)$ of the articles were submitted by researchers from South Korea, followed by those from China and Turkey ( $\mathrm{n}=31$, each). A majority of articles were submitted under the clinical article category (60.1\%), followed by the case report and review article categories (Fig. 2). The article type case report, however, was accepted for publication only once because the editorial committee decided to restrict the publi-

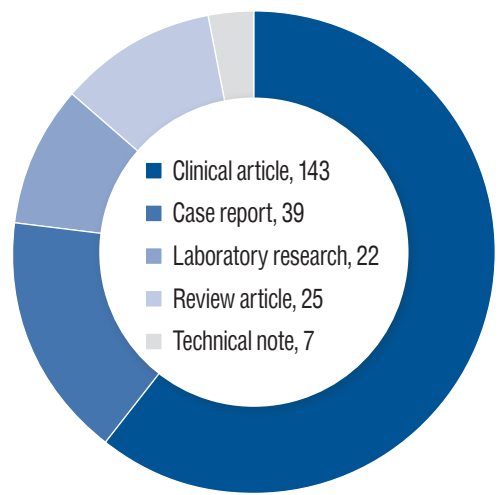

Fig. 2. Number of submitted articles stratified by article types in 2018.

- Received : December 17, 2018 •Revised : December 19, 2018 •Accepted : December 21, 2018

- Address for reprints : Bum-Tae Kim, M.D.

Department of Neurosurgery, Soonchunhyang University Bucheon Hospital, Soonchunhayng University College of Medicine 170 Jomaru-ro, Wonmi-gu, Bucheon 14584, Korea

Tel : +82-32-621-5059, Fax : +82-32-621-5016, E-mail : bumtkim@schmc.ac.kr

This is an Open Access article distributed under the terms of the Creative Commons Attribution Non-Commercial License (http://creativecommons.org/licenses/by-nc/4.0) which permits unrestricted non-commercial use, distribution, and reproduction in any medium, provided the original work is properly cited. 
cation of case reports per the JKNS policy. The acceptance rate of clinical articles, review articles, and laboratory research is $38.1 \%, 68.2 \%$, and $21.1 \%$, respectively.

\section{BEST REVIEWERS AWARD}

It cannot be denied that the contribution of the authors and editorial board members was very important. However, we believe that the dedication of the reviewers was the most critical factor for improving the relevance of our journal. Therefore, our editorial committee selected best reviewers to convey our gratitude to those who reviewed the papers submitted to our journals in the past year. Three aspects were considered in the selection of the best reviewers : numbers of paper reviewed, speed of the review, and quality of the review ${ }^{1,3)}$. We requested the editors of each section to recommend reviewers who provided good-quality review, and the review quality was determined by the recommendation list of the editors. We checked the reviewing records to determine the number of articles reviewed, and duration taken for the reviews. Finally, six reviewers were nominated for the JKNS best reviewer of 2018; each reviewer has contributed to the fields of stereotactic and functional, neurovascular, neurotrauma, brain tumor, spine, and pediatric neurosurgery. We would like to announce the best reviewers in an alphabetical order of their last names (Fig. 3).

$\begin{array}{ll}\text { Won Seok Chang } & \text { Jin Hwan Cheong } \\ \text { Yonsei University } & \text { Hanyang University } \\ \text { Stereotactic and functional } & \text { Neurovascular } \\ \text { Suk-Hyung Kang } & \text { Yong Hwy Kim } \\ \text { Hallym University } & \text { Seoul National University } \\ \text { Neurotrauma } & \text { Brain tumor } \\ \text { Joo Han Kim } & \text { Kyu-Chang Wang } \\ \text { Korea University } & \text { Seoul National University } \\ \text { Spine } & \text { Pediatric neurosurgery }\end{array}$

Although the editorial committee of JKNS selected only six reviewers for 2018, we would like to express our deep gratitude to all reviewers for their contribution to our journal.

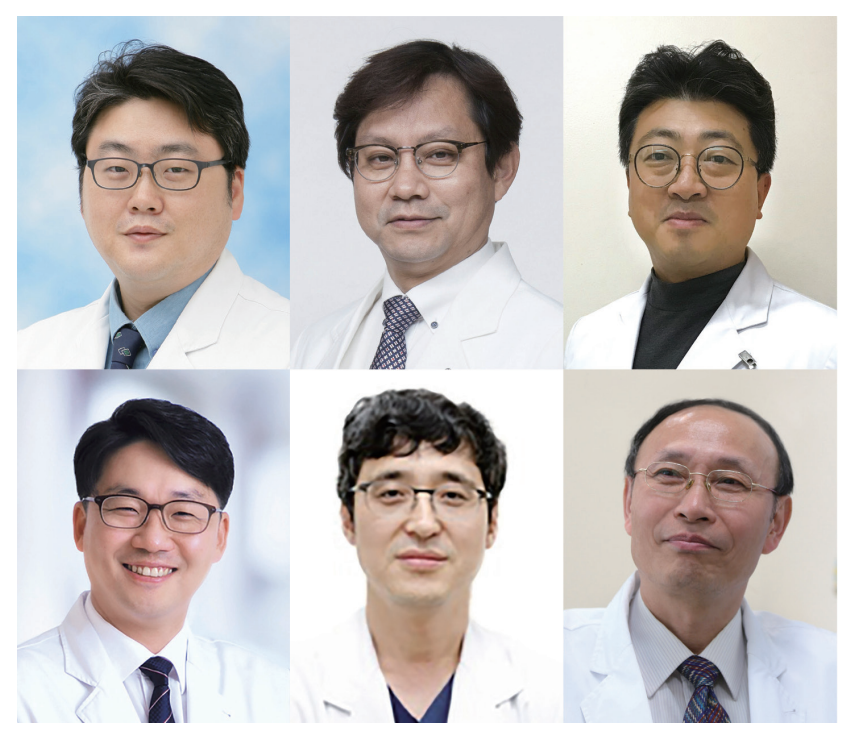

Fig. 3. The best reviewers from top left to bottom right: Won Seok Chang, Jin Hwan Cheong, Suk-Hyung Kang, Yong Hwy Kim, Joo Han Kim, Kyu-Chang Wang.

\section{CONFLICTS OF INTEREST}

No potential conflict of interest relevant to this article was reported.

\section{- Acknowledgements}

This work was supported by Korean Neurosurgical Society and Soonchunhyang University Research Fund.

\section{References}

1. Hong ST : Appreciations to peer reviewers for Journal of Korean Medical Science 2017. J Korean Med Sci 33 : e114, 2018

2. Kim BT, Chung $M$ : Evolution of quality improvement for the Journal of Korean Neurosurgical Society. J Korean Neurosurg Soc 61 : 425-426, 2018

3. Murohara $T$ : Editorial statistics and best reviewers award for 2017. Circ J 82 : 299-301, 2018 